\title{
Hybrid Double Perovskite Containing Helium: $\left[\mathrm{He}_{2}\right][\mathrm{CaZr}] \mathrm{F}_{6}$
}

\author{
Anthony J. Lloyd II, Brett R. Hester, ${ }^{\dagger}$ Samuel J. Baxter, ${ }^{\dagger}$ Shangye Ma, ${ }^{\dagger}$ Vitali B. \\ Prakapenka, ${ }^{\ddagger}$ Sergey N. Tkachev, ${ }^{\ddagger}$ Changyong Park, ${ }^{\%}$ and Angus P. Wilkinson ${ }^{*+, \S}$ \\ + School of Chemistry and Biochemistry, Georgia Institute of Technology, Atlanta, GA 30332-0400, United States \\ ${ }^{\S}$ School of Materials Science and Engineering, Georgia Institute of Technology, Atlanta, GA 30332-0245, United States \\ ${ }^{\ddagger}$ Center for Advanced Radiation Sources, University of Chicago, Chicago, Illinois 60637, United States \\ ${ }^{\%}$ HPCAT, X-ray Science Division, Argonne National Laboratory, Argonne, Illinois 60439, Unite States
}

\section{Contents:}

\section{Further synthetic details}

\section{List of Supplementary Figures}

Figure S1. Le Bail plot showing a fit of $\mathrm{CaZrF}_{6} \mathrm{Fm}_{3} \mathrm{~m}$ model to the powder x-ray diffraction data obtained in a diamond anvil cell at the initial helium gas loading pressure of $0.28 \mathrm{GPa}$. The high $\mathrm{Q}$ section has been scaled to show the details, but shifted downwards, so that the backgrounds for the sections of the plot appear to be the same. The phase flags denote $\mathrm{CaZrF}_{6}$ (magenta) and $\mathrm{CaF}_{2}$ (black).

Figure S2. Le Bail plot showing a fit of $\mathrm{CaZrF}_{6} \mathrm{Fm} 3 \mathrm{~m}$ model to the powder $\mathrm{x}$-ray diffraction data obtained in a diamond anvil cell at the initial helium gas loading pressure of $0.21 \mathrm{GPa}$. The high $\mathrm{Q}$ section has been scaled to show the details, but shifted downwards, so that the backgrounds for the sections of the plot appear to be the same. The phase flags denote $\mathrm{CaZrF}_{6}$ (magenta) and $\mathrm{NaCl}$ (black).

Figure S3. Bulk moduli for $\mathrm{He}_{2} \mathrm{CaZrF}_{6}$ at $300 \mathrm{~K}$ estimated from straight line fits to $\ln (V)$ versus $P$ over the pressure range a) 1.5 to $3.6 \mathrm{GPa}$ and b) 1.1 to $1.9 \mathrm{GPa}$. The two different lines on each plot show fits for the data collected using $\mathrm{NaCl}$ and $\mathrm{CaF}_{2}$ as the internal pressure calibrants.

Figure S4. Rietveld fits to the diffraction data recorded on $16 \mathrm{BM}$ with the DAC is a helium flow cryostat. A cubic model was used for the fits shown in panels a) thru d). The estimated pressures for the data were a) $1.25 \mathrm{GPa}$, b) $1.26 \mathrm{GPa}$, c) $1.42 \mathrm{GPa}$ and d) $1.52 \mathrm{GPa}$. The fit shown in e) uses a tetragonal model with data recorded at $2.90 \mathrm{GPa}$, which was the highest pressure attained at $15 \mathrm{~K}$. The magenta and blue tag marks indicate the calculated peak positions for the $\mathrm{CaZrF}_{6}$ and $\mathrm{CaF}_{2}$ respectively. The peaks marked with red dots were fit as part of the background as they come from a low crystallinity new phase that is observed on grinding cubic $\mathrm{CaZrF}_{6}$. As cubic $\mathrm{CaZrF}_{6} \mathrm{can}^{\prime} \mathrm{t}$ be readily ground down a low particle size, the above data suffer from problems associated with poor sampling statistics. A spot mask was used during integration in GSAS-II to reduce the extent of this problem, but it could not be completely eliminated. .. 5 


\section{List of Supplementary Tables}

Table S1. Unit cell volumes for cubic $\mathrm{CaZrF}_{6}$ and $\mathrm{CaF}_{2}$ in a helium-loaded diamond anvil cell as determined from Rietveld analyses of the high-pressure diffraction data. Pressures estimated from the unit cell volume of the $\mathrm{CaF}_{2}$ using an equation of state are also given.

Table S2. Unit cell volumes for cubic $\mathrm{CaZrF}_{6}$ and $\mathrm{NaCl}$ in a helium-loaded diamond anvil cell as determined from Le Bail analyses of the high-pressure diffraction data. Pressures estimated from the unit cell volume of the $\mathrm{NaCl}$ using an equation of state are also given.

Table S3. Values of $\mathrm{V}_{0}, \mathrm{~K}_{0}$ and $\mathrm{K}_{0}{ }^{\prime}$ that were used in a Birch-Murnaghan equation of state to determine pressure from the unit cell volume of the $\mathrm{NaCl}$ calibrant at low temperature.

Table S4. $\mathrm{CaZrF}_{6}$ and $\mathrm{NaCl}$ lattice constants and unit cell volumes as a function of temperature and pressure for the helium cryostat DAC experiment.

\section{Synthetic details}

The $\mathrm{CaZrF}_{6}$ used for the current study came from more than one synthetic batch. In general, our preparations are performed using commercial Nickel 200/201 seamless tube, sourced from Mega Mex. Humble, TX, USA. We have successfully used more than one size of tube, but an outside diameter of $1 / 2$ " is typical with a length of a few inches. Syntheses on a scale of $\sim 0.3$ to $\sim 5$ grams have been performed. The larger scale syntheses often give cleaner products. The nickel tubes are prepared by crushing one end, arc (TIG) welding that end in an argon atmosphere, and then cleaning in dilute $\mathrm{HCl}$ followed by a thorough wash in water. The mixed reactant powder is pressed into pellets. Pieces of the pellets are placed in the partially closed and cleaned tube. The open end of the tube is crimped closed using a hydraulic press in the glove box. The crimped tube in then transferred to the arc welding station and sealed by welding.

While no safety problems were encountered during the preparation of material for the current studies, in addition to taking typical precautions for handling fluorides that can react with moisture to produce $\mathrm{HF}$, it is important that the starting materials are dry and free from hydroxide. We have, in other syntheses, experienced a dangerous buildup of pressure inside nickel reaction tubes at high temperature, which may have been due to the presence of water and/or hydroxide in the starting materials 


\section{Supplementary Figures}

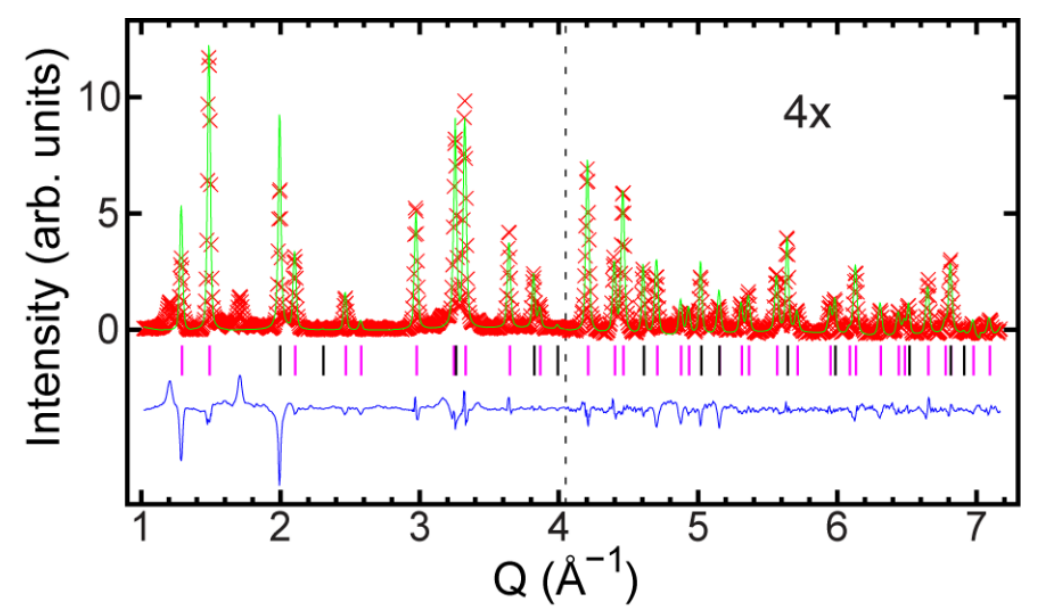

Figure S1. Le Bail plot showing a fit of $\mathrm{CaZrF}_{6} \mathrm{Fm} \overline{3} \mathrm{~m}$ model to the powder x-ray diffraction data obtained in a diamond anvil cell at the initial helium gas loading pressure of $0.28 \mathrm{GPa}$. The high $\mathrm{Q}$ section has been scaled to show the details, but shifted downwards, so that the backgrounds for the sections of the plot appear to be the same. The phase flags denote $\mathrm{CaZrF}_{6}$ (magenta) and $\mathrm{CaF}_{2}$ (black).

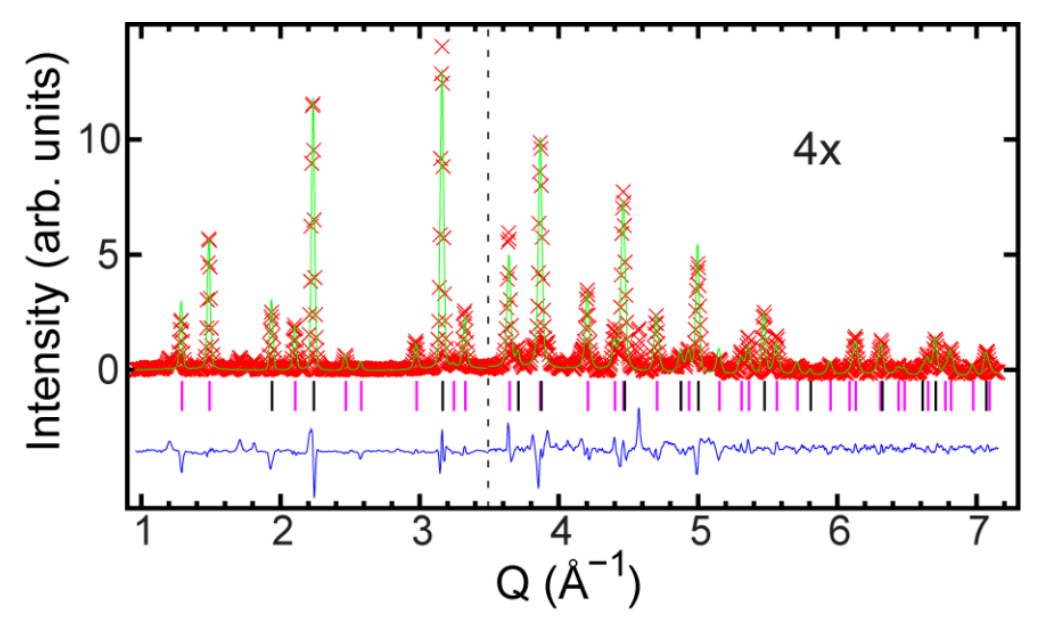

Figure S2. Le Bail plot showing a fit of $\mathrm{CaZrF}_{6} \mathrm{Fm} \overline{3} \mathrm{~m}$ model to the powder x-ray diffraction data obtained in a diamond anvil cell at the initial helium gas loading pressure of $0.21 \mathrm{GPa}$. The high $\mathrm{Q}$ section has been scaled to show the details, but shifted downwards, so that the backgrounds for the sections of the plot appear to be the same. The phase flags denote $\mathrm{CaZrF}_{6}$ (magenta) and $\mathrm{NaCl}$ (black). 

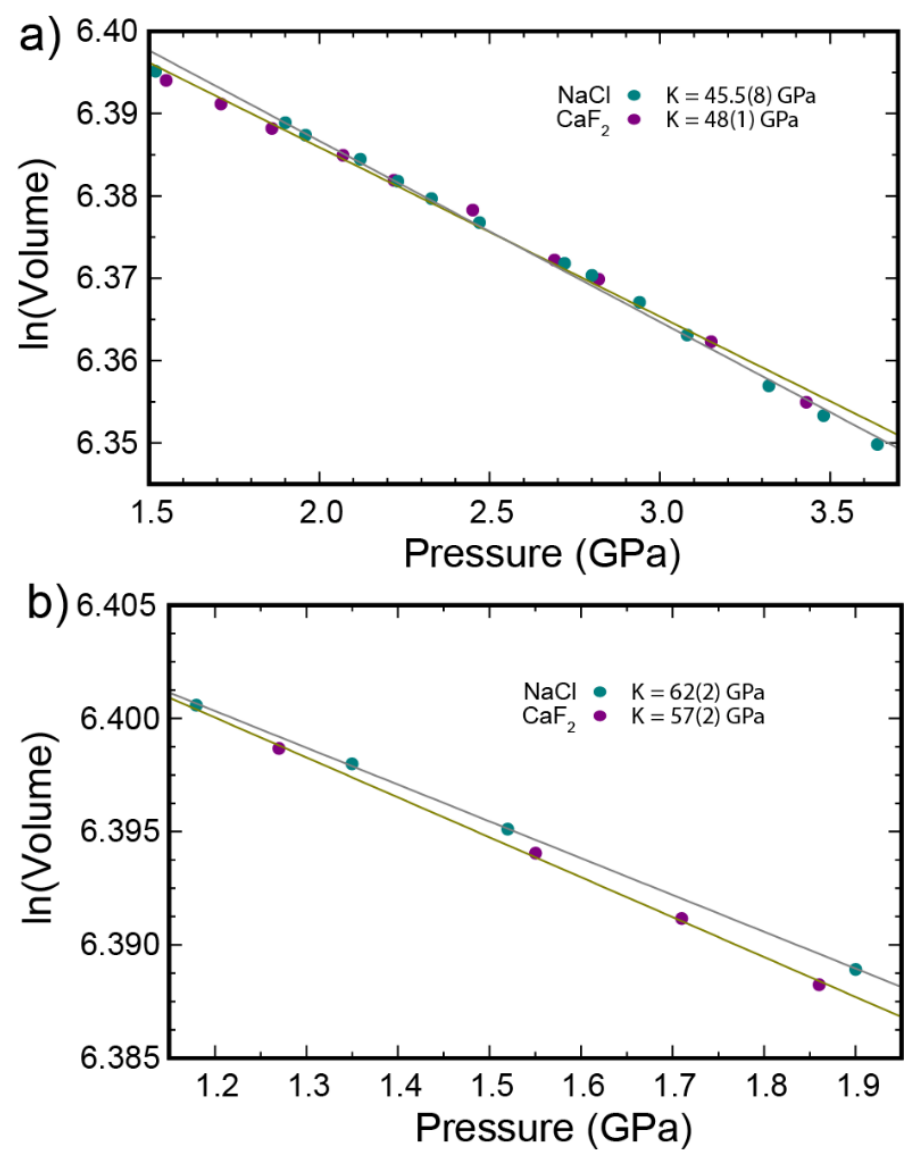

Figure S3. Bulk moduli for $\mathrm{He}_{2} \mathrm{CaZrF}_{6}$ at $300 \mathrm{~K}$ estimated from straight line fits to $\ln (V)$ versus $P$ over the pressure range a) 1.5 to $3.6 \mathrm{GPa}$ and b) 1.1 to $1.9 \mathrm{GPa}$. The two different lines on each plot show fits for the data collected using $\mathrm{NaCl}$ and $\mathrm{CaF}_{2}$ as the internal pressure calibrants. 
a)

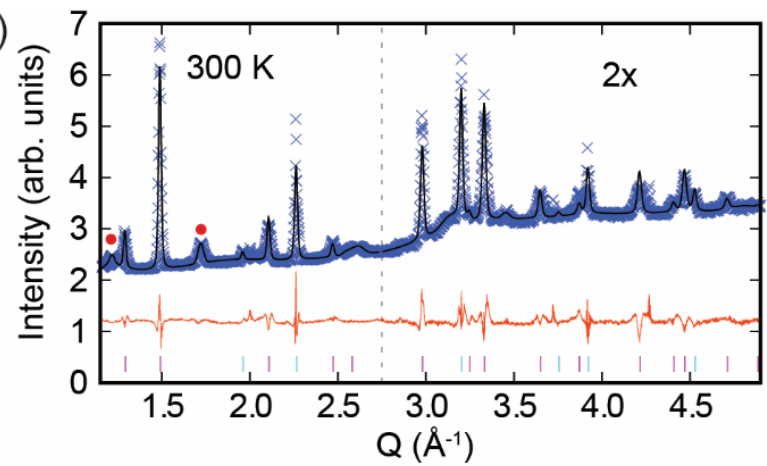

c)

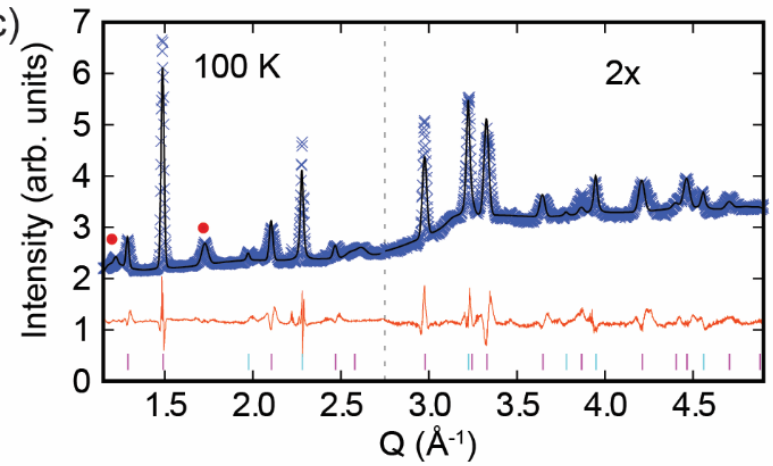

b)

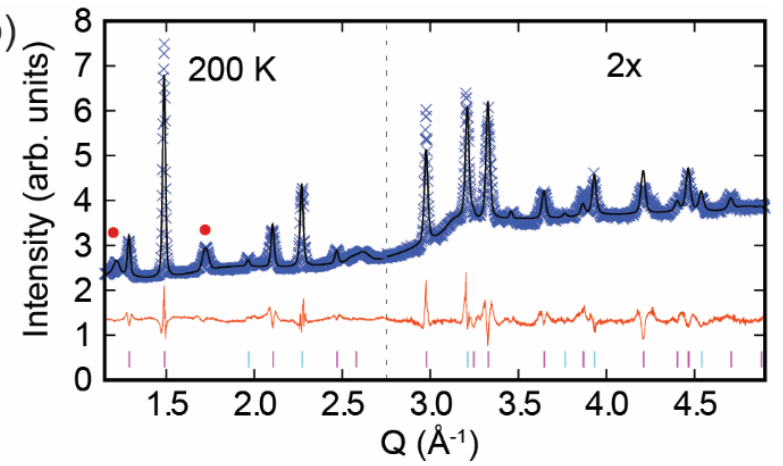

d)

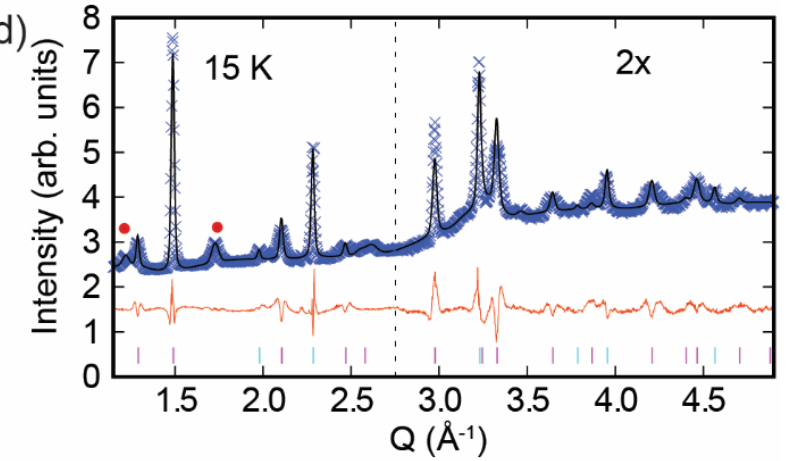

e)

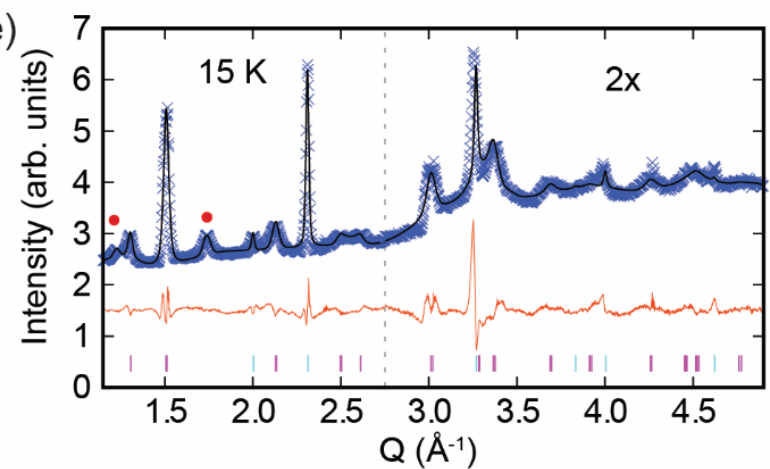

Figure S4. Rietveld fits to the diffraction data recorded on $16 \mathrm{BM}$ with the DAC is a helium flow cryostat. A cubic model was used for the fits shown in panels a) thru d). The estimated pressures for the data were a) $1.25 \mathrm{GPa}$, b) $1.26 \mathrm{GPa}$, c) $1.42 \mathrm{GPa}$ and d) $1.52 \mathrm{GPa}$. The fit shown in e) uses a tetragonal model with data recorded at $2.90 \mathrm{GPa}$, which was the highest pressure attained at $15 \mathrm{~K}$. The magenta and blue tag marks indicate the calculated peak positions for the $\mathrm{CaZrF}_{6}$ and $\mathrm{CaF}_{2}$ respectively. The peaks marked with red dots were fit as part of the background as they come from a low crystallinity new phase that is observed on grinding cubic $\mathrm{CaZrF}_{6}$. As cubic $\mathrm{CaZrF}_{6}$ can't be readily ground down a low particle size, the above data suffer from problems associated with poor sampling statistics. A spot mask was used during integration in GSAS-II to reduce the extent of this problem, but it could not be completely eliminated. 


\section{Supplementary Tables}

Table S1. Unit cell volumes for cubic $\mathrm{CaZrF}_{6}$ and $\mathrm{CaF}_{2}$ in a helium-loaded diamond anvil cell as determined from Rietveld analyses of the high-pressure diffraction data. Pressures estimated from the unit cell volume of the $\mathrm{CaF}_{2}$ using an equation of state are also given.

\begin{tabular}{|c|c|c|c|}
\hline $\begin{array}{c}\text { CaZrF } \\
\mathbf{a}(\mathbf{\AA})\end{array}$ & $\begin{array}{c}\mathrm{CaZrF}_{6} \\
\text { Volume }\left(\mathbf{\AA}^{\mathbf{3}} \mathbf{)}\right.\end{array}$ & $\begin{array}{c}\mathrm{CaF}_{\mathbf{2}} \\
\text { Volume }\left(\mathbf{\AA}^{\mathbf{3}} \mathbf{)}\right.\end{array}$ & $\begin{array}{c}\text { Pressure } \\
(\mathbf{G P a})\end{array}$ \\
\hline $8.4527(5)$ & $603.92(11)$ & $162.57(4)$ & $0.28(6)$ \\
\hline $8.4552(5)$ & $604.47(11)$ & $162.63(5)$ & $0.20(3)$ \\
\hline $8.4516(5)$ & $603.70(11)$ & $162.56(4)$ & $0.23(3)$ \\
\hline $8.4510(5)$ & $603.57(12)$ & $162.37(4)$ & $0.33(3)$ \\
\hline $8.4521(5)$ & $603.81(11)$ & $162.20(4)$ & $0.42(3)$ \\
\hline $8.4527(6)$ & $603.94(12)$ & $161.96(5)$ & $0.54(4)$ \\
\hline $8.4543(6)$ & $604.28(12)$ & $161.78(5)$ & $0.64(4)$ \\
\hline $8.4534(5)$ & $604.09(10)$ & $161.54(4)$ & $0.76(4)$ \\
\hline $8.4500(6)$ & $603.36(12)$ & $161.18(4)$ & $0.95(5)$ \\
\hline $8.4452(6)$ & $602.33(12)$ & $160.91(4)$ & $1.10(5)$ \\
\hline $8.4392(5)$ & $601.04(12)$ & $160.59(4)$ & $1.27(6)$ \\
\hline $8.4263(5)$ & $598.28(10)$ & $160.08(4)$ & $1.55(7)$ \\
\hline $8.4182(5)$ & $596.56(11)$ & $159.80(4)$ & $1.71(8)$ \\
\hline $8.4099(6)$ & $594.80(13)$ & $159.54(5)$ & $1.86(8)$ \\
\hline $8.4006(5)$ & $592.84(11)$ & $159.16(5)$ & $2.07(9)$ \\
\hline $8.3922(6)$ & $591.05(12)$ & $158.90(5)$ & $2.22(9)$ \\
\hline $8.3820(6)$ & $588.90(12)$ & $158.51(5)$ & $2.45(10)$ \\
\hline $8.3652(6)$ & $585.37(13)$ & $158.12(4)$ & $2.69(11)$ \\
\hline $8.3585(6)$ & $583.97(13)$ & $157.90(5)$ & $2.82(11)$ \\
\hline $8.3376(6)$ & $579.59(13)$ & $157.37(5)$ & $3.15(13)$ \\
\hline $8.3170(7)$ & $575.31(14)$ & $156.91(5)$ & $3.43(14)$ \\
\hline
\end{tabular}


Table S2. Unit cell volumes for cubic $\mathrm{CaZrF}_{6}$ and $\mathrm{NaCl}$ in a helium-loaded diamond anvil cell as determined from Le Bail analyses of the high-pressure diffraction data. Pressures estimated from the unit cell volume of the $\mathrm{NaCl}$ using an equation of state are also given.

\begin{tabular}{|c|c|c|c|}
\hline $\begin{array}{l}\mathrm{CaZrF}_{6} \\
\mathrm{a}(\AA)\end{array}$ & $\begin{array}{c}\text { CaZrF }_{6} \\
\text { Volume }\left(\AA^{3}\right)\end{array}$ & $\begin{array}{c}\mathrm{NaCl} \\
\text { Volume }\left(\AA^{3}\right)\end{array}$ & $\begin{array}{c}\text { Pressure } \\
\text { (GPa) }\end{array}$ \\
\hline $8.4544(6)$ & $604.3(14)$ & $177.89(3)$ & $0.21(6)$ \\
\hline $8.4538(6)$ & $604.16(14)$ & $177.76(3)$ & $0.23(6)$ \\
\hline $8.4518(5)$ & $603.77(11)$ & $177.75(3)$ & $0.23(6)$ \\
\hline $8.4528(5)$ & $603.92(11)$ & $177.58(3)$ & $0.25(6)$ \\
\hline $8.4509(4)$ & $603.54(9)$ & $177.36(3)$ & $0.29(6)$ \\
\hline $8.4518(5)$ & $603.67(10)$ & $177.04(5)$ & $0.33(8)$ \\
\hline $8.4520(5)$ & $603.77(10)$ & $176.78(3)$ & $0.37(7)$ \\
\hline $8.4517(5)$ & $603.71(12)$ & $176.51(4)$ & $0.41(7)$ \\
\hline $8.4520(8)$ & $603.78(16)$ & $176.15(5)$ & $0.46(8)$ \\
\hline $8.4532(5)$ & $604.03(10)$ & $175.84(3)$ & $0.51(7)$ \\
\hline $8.4533(5)$ & $604.06(10)$ & $175.41(4)$ & $0.57(7)$ \\
\hline $8.4549(4)$ & $604.40(9)$ & $174.94(3)$ & $0.65(7)$ \\
\hline $8.4553(4)$ & $604.48(10)$ & $174.60(4)$ & $0.70(7)$ \\
\hline $8.4541(5)$ & $604.24(11)$ & $174.11(4)$ & $0.78(8)$ \\
\hline $8.4533(5)$ & $604.05(11)$ & $173.69(4)$ & $0.84(8)$ \\
\hline $8.4515(5)$ & $603.68(10)$ & $172.90(4)$ & $0.97(8)$ \\
\hline $8.4480(5)$ & $602.93(11)$ & $172.33(3)$ & $1.07(7)$ \\
\hline $8.4446(5)$ & $602.19(10)$ & $171.71(3)$ & $1.18(8)$ \\
\hline $8.4373(5)$ & $600.64(10)$ & $170.71(3)$ & $1.35(8)$ \\
\hline $8.4293(5)$ & 598.92(10) & $169.79(3)$ & $1.52(8)$ \\
\hline $8.4119(6)$ & $595.22(13)$ & $167.80(4)$ & $1.90(9)$ \\
\hline $8.4074(5)$ & $594.28(11)$ & $167.51(3)$ & $1.96(9)$ \\
\hline $8.3995(4)$ & $592.59(10)$ & $166.73(3)$ & $2.12(8)$ \\
\hline $8.3920(5)$ & $591.00(10)$ & $166.18(4)$ & $2.23(9)$ \\
\hline $8.3861(4)$ & $589.76(9)$ & $165.68(4)$ & $2.33(10)$ \\
\hline $8.3780(5)$ & $588.05(11)$ & $165.06(4)$ & $2.47(10)$ \\
\hline $8.3640(5)$ & $585.12(10)$ & $163.91(3)$ & $2.72(10)$ \\
\hline $8.3599(5)$ & $584.26(10)$ & $163.57(3)$ & $2.80(10)$ \\
\hline $8.3509(5)$ & $582.38(11)$ & $162.96(3)$ & $2.94(10)$ \\
\hline $8.3397(7)$ & $580.03(14)$ & $162.37(4)$ & $3.08(12)$ \\
\hline $8.3225(6)$ & $576.46(12)$ & $161.36(3)$ & $3.32(11)$ \\
\hline $8.3126(8)$ & $574.40(16)$ & $160.72(4)$ & $3.48(11)$ \\
\hline $8.3028(11)$ & $572.37(22)$ & $160.08(4)$ & $3.64(12)$ \\
\hline
\end{tabular}


Table S3. Values of $\mathrm{V}_{0}, \mathrm{~K}_{0}$ and $\mathrm{K}_{0}{ }^{\prime}$ that were used in a Birch-Murnaghan equation of state to determine pressure from the unit cell volume of the $\mathrm{NaCl}$ calibrant at low temperature.

\begin{tabular}{|c|c|c|c|}
\hline Temperature (K) & $\mathbf{V}_{\mathbf{0}}\left(\AA^{\mathbf{3}} \mathbf{)}\right.$ & $\mathbf{K}_{\mathbf{0}}(\mathbf{G P a})$ & $\mathbf{K}_{\mathbf{0}}{ }^{\mathbf{1}}$ \\
\hline 15 & 175.30 & 27.6 & 5 \\
\hline 100 & 175.86 & 26.6 & 5 \\
\hline 200 & 177.54 & 25.3 & 5 \\
\hline 300 & 179.44 & 23.8 & 5 \\
\hline
\end{tabular}

Table S4. $\mathrm{CaZrF}_{6}$ and $\mathrm{NaCl}$ lattice constants and unit cell volumes as a function of temperature and pressure for the helium cryostat DAC experiment.

\begin{tabular}{|c|c|c|c|c|c|}
\hline $\begin{array}{l}\text { Temperature } \\
\text { (K) }\end{array}$ & $\begin{array}{c}\text { Pressure } \\
\text { (GPa) }\end{array}$ & $\begin{array}{c}\text { Lattice } \\
\text { constant, a (Å) }\end{array}$ & $\begin{array}{c}\text { Lattice } \\
\text { constant, c (Å) }\end{array}$ & $\begin{array}{c}\text { Unit cell volume } \\
\text { sample }\left(\AA^{3}\right)\end{array}$ & $\begin{array}{l}\text { Unit cell volume } \\
\qquad \mathrm{NaCl}\left(\AA^{3}\right)\end{array}$ \\
\hline 300 & $0.239(2)$ & $8.4599(3)$ & & $605.47(7)$ & $177.69(4)$ \\
\hline 300 & $0.392(4)$ & $8.4553(2)$ & & $604.49(4)$ & $176.62(2)$ \\
\hline 300 & $0.541(6)$ & $8.4560(2)$ & & $604.64(4)$ & $175.62(2)$ \\
\hline 300 & $0.74(1)$ & $8.4568(2)$ & & $604.81(4)$ & $174.30(1)$ \\
\hline 300 & $0.85(1)$ & $8.4545(2)$ & & $604.32(4)$ & 173.61(1) \\
\hline 300 & $1.08(2)$ & $8.4482(2)$ & & $602.97(4)$ & $172.22(2)$ \\
\hline 300 & $1.24(3)$ & $8.4433(2)$ & & $601.91(4)$ & $171.33(2)$ \\
\hline 300 & $1.44(4)$ & $8.4347(2)$ & & $600.08(4)$ & $170.19(2)$ \\
\hline 300 & $1.61(5)$ & $8.4273(2)$ & & $598.51(5)$ & $169.24(2)$ \\
\hline 300 & $1.78(6)$ & $8.4196(2)$ & & $596.86(5)$ & $168.37(1)$ \\
\hline 300 & $1.99(7)$ & $8.4095(2)$ & & $594.72(5)$ & $167.30(1)$ \\
\hline 300 & $2.21(8)$ & $8.3974(2)$ & & $592.15(5)$ & $166.18(1)$ \\
\hline 300 & $1.25(3)$ & $8.4304(7)$ & & $600.58(6)$ & $171.24(2)$ \\
\hline 200 & $2.10(7)$ & $8.4043(2)$ & & $593.62(5)$ & $165.57(1)$ \\
\hline 200 & $2.03(7)$ & $8.4086(2)$ & & $594.54(5)$ & $165.93(1)$ \\
\hline 200 & $1.89(6)$ & $8.4143(2)$ & & $595.75(5)$ & $166.57(1)$ \\
\hline 200 & $2.07(7)$ & $8.4024(2)$ & & $593.22(5)$ & $165.75(1)$ \\
\hline 200 & $2.19(8)$ & $8.3963(2)$ & & $591.93(4)$ & $165.19(1)$ \\
\hline 200 & $2.32(9)$ & $8.3903(2)$ & & $590.65(5)$ & $164.59(1)$ \\
\hline 200 & $1.77(5)$ & $8.4198(2)$ & & $596.91(5)$ & 167.19(1) \\
\hline 200 & $1.12(2)$ & $8.4500(3)$ & & $603.36(6)$ & $170.59(2)$ \\
\hline 200 & $1.26(3)$ & $8.4458(3)$ & & $602.44(6)$ & $169.80(3)$ \\
\hline 200 & $1.44(4)$ & $8.4410(3)$ & & $601.43(6)$ & $168.87(3)$ \\
\hline 100 & $0.96(2)$ & $8.4648(3)$ & & $606.52(6)$ & $170.14(2)$ \\
\hline 100 & $1.01(2)$ & $8.4622(3)$ & & $605.97(6)$ & $169.85(2)$ \\
\hline 100 & $1.07(2)$ & $8.4601(3)$ & & $605.51(6)$ & $169.55(3)$ \\
\hline 100 & $1.17(2)$ & $8.4569(3)$ & & $604.83(7)$ & $169.00(3)$ \\
\hline 100 & $1.32(3)$ & $8.4523(3)$ & & $603.85(7)$ & $168.24(3)$ \\
\hline 100 & $1.47(4)$ & $8.4460(4)$ & & $602.50(8)$ & $167.46(3)$ \\
\hline
\end{tabular}




\begin{tabular}{|l|l|l|l|l|l|}
\hline 100 & $1.69(5)$ & $8.4384(4)$ & & $600.86(8)$ & $166.40(3)$ \\
\hline 100 & $1.90(6)$ & $8.4293(4)$ & & $598.92(9)$ & $165.40(3)$ \\
\hline 100 & $1.93(6)$ & $8.4253(5)$ & & $598.1(1)$ & $165.26(2)$ \\
\hline 100 & $1.42(3)$ & $8.4468(3)$ & & $602.66(7)$ & $167.73(3)$ \\
\hline 100 & $0.96(2)$ & $8.4648(3)$ & & $606.52(6)$ & $170.14(2)$ \\
\hline 15 & $1.25(3)$ & $8.4624(4)$ & & $606.00(9)$ & $168.26(3)$ \\
\hline 15 & $1.29(3)$ & $8.4600(4)$ & & $605.50(9)$ & $168.07(3)$ \\
\hline 15 & $1.32(3)$ & $8.4586(4)$ & & $605.19(9)$ & $167.94(3)$ \\
\hline 15 & $1.35(3)$ & $8.4571(4)$ & & $604.87(9)$ & $167.78(3)$ \\
\hline 15 & $1.40(3)$ & $8.4548(4)$ & & $604.37(9)$ & $167.53(3)$ \\
\hline 15 & $1.46(3)$ & $8.4518(4)$ & & $603.74(9)$ & $167.25(3)$ \\
\hline 15 & $1.52(4)$ & $8.4480(4)$ & & $602.92(9)$ & $166.94(3)$ \\
\hline 15 & $1.61(4)$ & $8.4426(5)$ & & $601.8(1)$ & $166.54(3)$ \\
\hline 15 & $1.72(5)$ & $8.4358(5)$ & & $600.3(1)$ & $166.03(3)$ \\
\hline 15 & $1.79(5)$ & $8.4314(6)$ & & $599.4(1)$ & $165.69(3)$ \\
\hline 15 & $1.99(6)$ & $5.956(1)$ & $8.421(1)$ & $298.8(1)$ & $164.80(3)$ \\
\hline 15 & $2.06(7)$ & $5.953(2)$ & $8.414(1)$ & $298.2(1)$ & $164.47(3)$ \\
\hline 15 & $2.20(7)$ & $5.945(2)$ & $8.402(1)$ & $296.9(2)$ & $163.89(3)$ \\
\hline 15 & $2.26(8)$ & $5.944(2)$ & $8.394(1)$ & $296.6(2)$ & $163.63(3)$ \\
\hline 15 & $2.37(8)$ & $5.936(2)$ & $8.384(2)$ & $295.4(2)$ & $163.17(3)$ \\
\hline 15 & $2.7(1)$ & $5.924(2)$ & $8.344(2)$ & $292.8(2)$ & $161.70(3)$ \\
\hline 15 & $2.7(1)$ & $5.924(2)$ & $8.344(2)$ & $292.8(2)$ & $161.67(3)$ \\
\hline 15 & $2.8(1)$ & $5.910(3)$ & $8.341(2)$ & $291.3(2)$ & $161.38(3)$ \\
\hline 15 & $2.9(1)$ & $5.906(3)$ & $8.323(2)$ & $290.4(2)$ & $160.93(3)$ \\
\hline
\end{tabular}

